\title{
Educating Innovators of Future Internet of Things
}

\author{
Evgeny Osipov, Laurynas Riliskis \\ Department of Computer Science, Electrical and Space Engineering \\ Luleå University of Technology \\ 97187 Luleå, Sweden \\ \{Evgeny.Osipov, Laurynas.Riliskis\}@1tu.se
}

\begin{abstract}
The concept of "Internet-of-Things" will undoubtedly emerge as the technology of the future. Educating specialists ready to bring the concept to the reality remains challenging in the scope of traditional university courses. The main challenge is how to enable students to think outside the boundaries of the particular discipline and therefore to enable the innovative thinking. This article describes an experiment with teaching Internetof-Things as a common red thread across three courses which ran in parallel during fall semester 2012 at Luleå University of Technology in Sweden. We discuss the teaching methodology, the technology blocks which laid the ground for our teaching philosophy as well as the experiences and lessons learned.
\end{abstract}

\section{INTRODUCTION}

While the term "Internet of things" (IoT) was coined for quite a while now, a systematic education of specialists in this area has not yet taken off. Traditionally, courses in Computer Science programs at universities offer a standard set of disciplines focusing on specific aspects of the IoT technology. The courses vary from different flavors of hardwarenear "Wireless Sensor Networks" classes to higher-level "WebDesign and Service Oriented Architectures" and similar. The demonstration of a place of the particular discipline in the holistic view of the IoT universe is often rather vague and in many cases is limited to one or two theoretical classes discussing problematics of adjacent subjects. This is in no way a surprising situation. Prior to all, the IoT concept only now starts to grow out of its embryonic, academic research phase. It is today it begins to be filled in with specific implementations.

One message is important to convey to students already now - the future of IoT technologies is about: a.) Innovations; b.) Cross-disciplinary knowledge; and c.) Multi-face programming. These principles formed the ground for an educational experiment conducted at Luleå University of Technology in the fall semester of 2012. During the experiment, further in the text referred to as triple-run, three courses of the Computer Science program were aligned in their theoretical and practical parts to convey a holistic view of an IoT ecosystem. The classes were taught in parallel.

The theoretical content of the three courses allowed creating a scenario covering the entire technology chain of the Internet of Things: gathering and communicating sensory data; scalable and distributed processing of big data; value-added, human relevant network services. In the practical part students in the three classes (60 in total) acted as startup companies in the respective technology domain. These startups were assigned a task to deliver a common holistic system given time, performance and budget constrains. This task required students in a particular course to constantly communicate to other students outside the courses boundaries. In particular, through these activities students were trained on skills for industrial level development and integration of complex IT systems and innovative thinking by exploring problems, methods and solution spaces of each other.

On the technical side the triple-run experiment was conducted using Amazon Web Services ${ }^{1}$ as a common computing platform. This choice allowed us to draw interesting conclusions about students work load, the degree of their actual involvement in the learning process as well as the cost of the triple-run. A pedagogy-oriented and close-to-reality real-time simulation environment was used in Wireless sensor networks course included in the triple-run experiment to substantially facilitate experimentation with large quantities of communicating sensors. This simulation environment is our main technical contribution supporting teaching of principles and advances of "communicating things".

The article is organised as follows. Section II elaborates the theoretical background and the related work. The syllabi of the courses under the experiment are summarised in Section III. The scenario behind the triple-run trial is described in Section IV. Section V presents the technology blocks used in the experiment. We present our reflections and outline future developments in Section VI before concluding the article in Section VII.

\section{THEORETICAL FOUNDATION OF THE TRIPLE-RUN EXPERIMENT AND RELATED WORK}

It would not be a big discovery to make that one of the largest motivating factors for today's Computer Science students is their excitement about the success of young innovators behind such IT giants as Facebook, Google, Skype and similar. The key to success is on the one hand evident: It is the innovative thinking, entrepreneurship and team-work. On the other hand, it is less evident how to foster such skills in the framework of the traditional education system.

The importance of empowering students with tools and opportunities to exploit the knowledge and to stimulate selflearning is reflected in many sources on modern methodologies in higher education. For example, [1], [2] asserts that by giving students tools, guidance and freedom as part of contextual understanding the educators encourage both innovation and the spirit of entrepreneurship. Commonly a range of studentcentered education methods where learning is supported by projects, problems of discovery nature and just in-time teaching is referred to as inductive education [3]. The goal of

\footnotetext{
${ }^{1}$ Amazon AWS website, [Online]. Available: http://aws.amazon.com.
} 
TABLE I. SUMMARY OF COURSES' SYLLABI before THE TRIPLE-RUN EXPERIMENT

\begin{tabular}{|c|c|c|c|}
\hline & \multicolumn{3}{|c|}{ Courses } \\
\hline & D7015E & D7001D & D0036D \\
\hline Credits & \multicolumn{3}{|c|}{7.5 ECTS } \\
\hline Level & \multicolumn{2}{|c|}{ Graduate. First year of MSc. } & Undergraduate. Second year. \\
\hline Goal & $\begin{array}{l}\text { The student should know fundamentals of modern } \\
\text { short range radio transmission technologies on } \\
\text { all layers of the communication stack and the } \\
\text { specifics of WSN network architecture like data- } \\
\text { centric communications, in-network processing, } \\
\text { etc. The student should be able to understand } \\
\text { research articles in selected areas of the course } \\
\text { and be able to present their analysis for a wider } \\
\text { audience. } \\
\text { The student should develop skills of modeling } \\
\text { an advanced networking functionality as well as } \\
\text { developing it in one of the main-stream operating } \\
\text { systems for WSN. }\end{array}$ & $\begin{array}{l}\text { The student should understand the fundamentals } \\
\text { distributed networked applications, e.g. in-depth } \\
\text { understanding of threads and associated perfor- } \\
\text { mance problems, fundamentals of fault detection } \\
\text { in distributed application, etc. The student should } \\
\text { be able to understand research articles in selected } \\
\text { areas of the course and be able to present their } \\
\text { analysis for a wider audience. } \\
\text { The student should master the skills of program- } \\
\text { ming of parallel events with threads, timers, coun- } \\
\text { ters and communication security in Java program- } \\
\text { ming language. }\end{array}$ & $\begin{array}{l}\text { The student should understand fundamentals of } \\
\text { network programming including relevant aspects } \\
\text { of TCP/IP stack, main communication paradigms, } \\
\text { basics of threads, sockets and remote method } \\
\text { invocation. } \\
\text { The students should develop skills of program- } \\
\text { ming a simple to medium complex network func- } \\
\text { tionality, e.g. a threaded TCP server and a simple } \\
\text { networking computer game with in-advance pre- } \\
\text { pared skeleton of the functionality. }\end{array}$ \\
\hline Structure & \multicolumn{2}{|l|}{ In-class lectures, student seminars and practical work. } & Lectures and practical work. \\
\hline Examination & $\begin{array}{l}\text { Continuous examination. Final score is computed } \\
\text { as a weighted average of the score in three exami- } \\
\text { nation moments: Labs, Seminar and Mini-project. }\end{array}$ & Traditional closed book final written exam. & \\
\hline
\end{tabular}

inductive education is to develop essential social and teamwork skills [4] by tackling real-world and open-end problems [5] which is is highly appreciated by students [6].

In our triple-run experiment we combined the inductive collaborative learning approach with the product-based learning. One of the important goals set to students were understanding project management and production processes. This approach applied previously in computer science education [7] showed positive results and is highly valued by industry.

Finally, we followed concepts of adaptive expertise or deep learning [8], [9] enabling students to motivate their solutions both from the technology and economical perspectives.

\section{A. Related work}

Clearly, we are not alone looking at the problematic of educating innovators of the future Internet of Things. A very recent work (as of February 2013) from the Open University in the UK [10] build their education approach using similar motivation. The work also includes the references to other world-leading schools in the US and Europe being active in the development of the IoT directed education lines. While sharing common objectives and parts of the methodologies our experiment described in this article is, however, different in several important ways:

1) We are not developing a single overview course, instead we make students from three focused courses to interact and collaborate with each other in the scope of a common IoT vision.

2) We target students with diverse backgrounds aligning the courses on the second year bachelor and the last year master levels. This step allows students on lower education stages to get insight to the diversity of problems considered at higher stages.

3) We do not use play environments, our students work with real software and hardware platforms which they later on meet on the job market.
The key points listed above make our experiment a unique contribution to the methodology of education in the area of the Internet of Things.

\section{COURSES UNDER EXPERIMENT}

The courses selected for the triple-run experiment were: Wireless sensor networks, further referred to by its catalogue code D7015E for brevity reasons; Network programming and distributed applications, further referred to as D7001D; and Network programming, further referred as D0036D. In the Swedish education system an academic year is divided in quarters (teaching periods). The duration of each quarter is 2 months. A regular course span over one quarter. The triplerun experiment was conducted in the first quarter of 2012 starting from the last week of August and ending with the exam week on the last week of October. Table I summarises relevant aspects of the courses' syllabi as of before the experiment. While the theoretical part and the goals of the syllabi remained unchanged, the practical part and the emphasis of the courses was shifted to IoT enabling technologies.

By the time of the experiment the D7015E course was given at two occasions in 2008 and 2010. The previous results of the course evaluation for both occasions were positive. On a methodology side the students highly evaluated the continuous form of examination, highlighting that this examination form assisted them in pacing their learning process properly and overly contributed to better learning. On a criticism side the students continuously highlighted difficulties with timeconsuming programming and debugging of the code on real wireless sensor devices in foreign for them development environment. During the triple-run experiment we decided to adopt the continuous examination form in all three courses.

The common to both D7001D and D0036D courses problems were shortcomings associated with lab infrastructures required to perform the practical parts. Although both courses are based on Java programming language, proper access rights to low-layers network configuration facilities were needed. In many cases students resorted to experimenting with very 


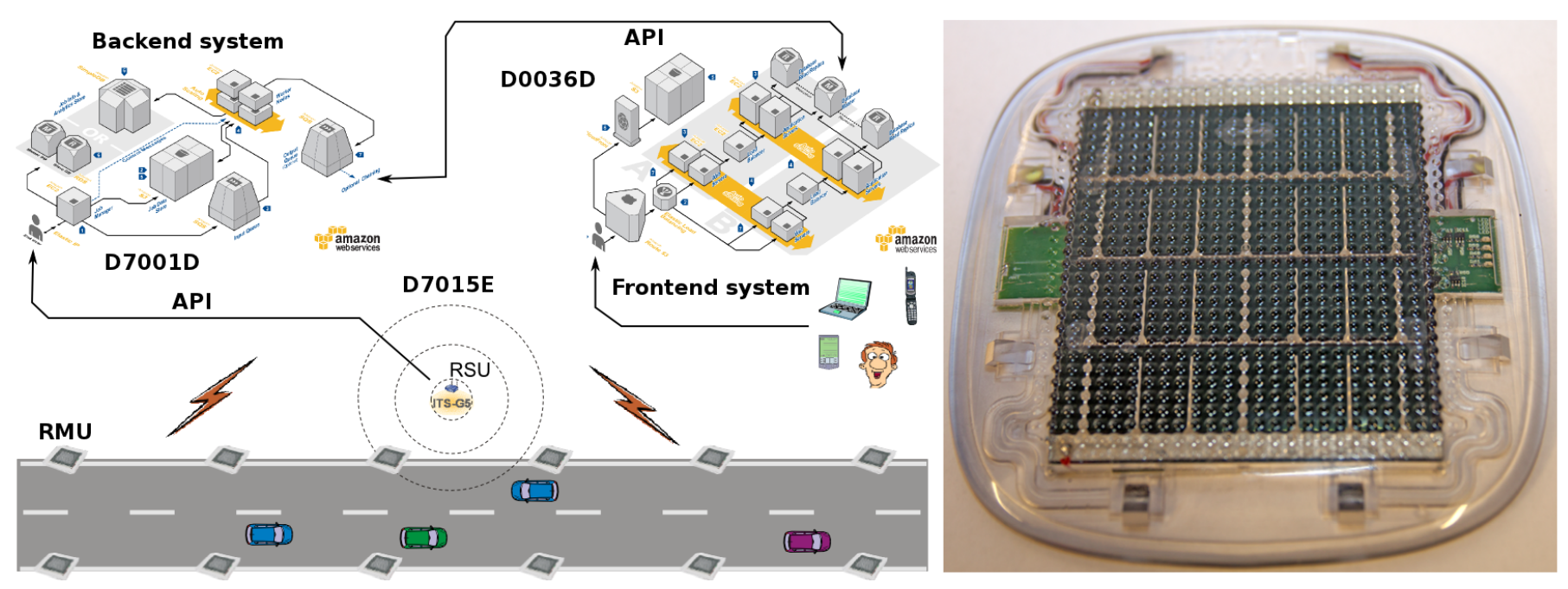

Fig. 1. A graphical representation of the scenario for the triple-run experiment.

simple network topologies basically consistent of their own computers (where they had the appropriate rights) and few hosts in the university network. In general, we the course instructors experienced major differences in developing nontrivial practical scenarios linking to the theoretical content of the course. The typical course-book-like code examples constantly raised students' critique as missing sufficient connection to real-life applications. The major change in the syllabi of the D0036D and D7001D courses was introducing the "Cloud" and the "Internet of Things" topics as the main themes both into their theoretical and practical parts. Looking ahead, by performing the practical part of the courses in the Amazon Web Services environment lifted up students' satisfaction and their experience of programming networking functionality dramatically.

\section{THE triple-run STRUCTURE}

The theoretical content of three courses described above allowed creating a scenario covering the whole technology chain of the Internet of Things: gathering and communicating sensory data; scalable and distributed processing of Big Data; value-added, human relevant network services.

\section{A. Common IoT scenario script}

The offered to the students common IoT scenario is rooted in the ongoing at LTU research project iRoad ${ }^{2}$. In short the project aims at enabling a non-intrusive and anonymous detection of vehicles using on road sensor networks [11]. The core of the iRoad technology is a specially designed Road Marking Unit, which is shown in the right part of Figure 1. It consists of a wireless sensor unit built on 16-bits Renessas microcontroller and put in a specially designed robust polymer casing resistant to overriding by heavy vehicles. The RMU is equipped with a magnetometer sensor and a ZigBee-compatible low power radio transceiver. Technologically, the RMUs are thermally glued onto the road surface. After that they detect vehicles by sampling the readings of the magnetometer. The samples

\footnotetext{
${ }^{2}$ iRoad project. [Online] Available: http://www.iroad.se
}

are then transmitted via a gateway serving several such RMUs to a powerful computing backend system for advanced signal processing and execution of application-specific functions. While in the scope of the project we performed installations with several tens nodes ${ }^{3}$, within the triple-run experiments we let students to work with virtually unlimited number of such sensors generating realistic traffic.

The overall concept behind the triple-run application scenario is shown in Figure 1. The students in the three courses were treated as start-up companies getting a contract to develop a part of the global IoT system. In particular, the start-up of the D7015E course was responsible for organisation of communications from RMUs to the gateway and from the gateway to the back-end system. The D7001D start-up was responsible for the design and development of a scalable cloud-based architecture for real-time processing and storage of the incoming data as well for serving the requests coming from a front-end system. Finally, the D0036D start-up was responsible for the implementation of a scalable web-based front-end system visualising the results of the computations. It is essential to note that on all stages of the project the students were faced with the real data traffic as it would come from real physical devices, see Section V for more information.

\section{B. Implementation}

The work flow of the triple-run experiment is illustrated in Figure 2. The classical style lectures gave students the theoretical skeleton of the courses' content. The first three introductory lectures were common to all three courses. Besides the introduction of the triple-run concept the common lectures gave a crash course on machine-to-machine communications, the Internet-of-Things ecosystem and the basics of the cloud computing using Amazon Web Services. After the introductory lectures all three courses followed their own lanes in the lecture part. All lectures in the three courses, however, were

\begin{tabular}{cccc}
\hline $\begin{array}{c}\text { 3iRoad project's demonstrator } \\
\text { http://www.youtube.com/watch?v=GYyWkYfsJhk }\end{array}$ & [Online] & Available: \\
\end{tabular}




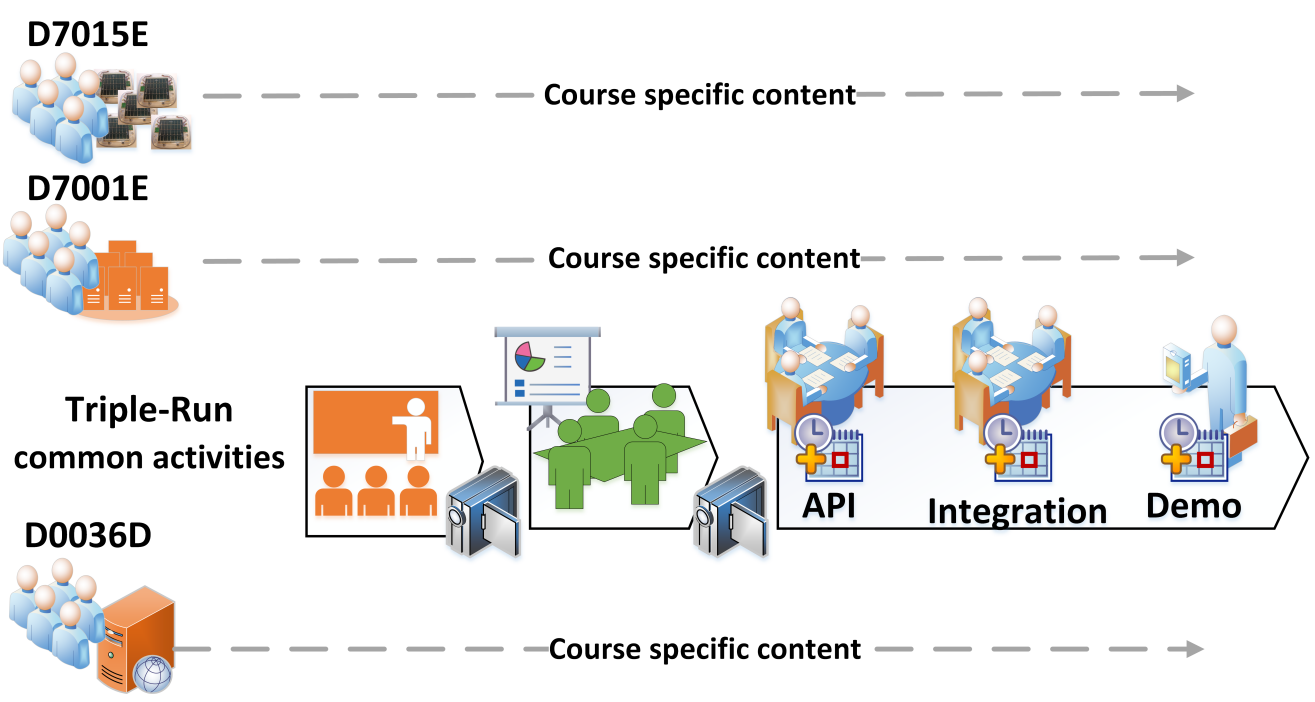

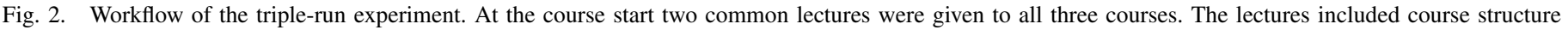

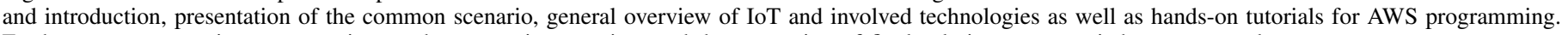
Further, common seminar presentations and concertation meeting, and demonstration of final solution were carried out commonly.

recorded using the Adobe Connect ${ }^{4}$ facility and the recordings were available in a common to all three courses space of elearning system Fronter ${ }^{5}$. This step allowed interested students of the particular course an option of following selected parts of another course.

The seminar series of the MSc-level courses D7001D and D7015E were made open to students of all three classes. The students could either attend the events physically as an optional course moment or watch the recorded presentations off-line. The themes offered for student seminars in the particular course aimed at presenting different design choices on selected functionalities, which later on should be developed by students in the practical part. For students from other courses attending the seminars, the aim was to introduce them to the world of the adjacent course. Not completely unexpected we were happy to observe that 20 to $30 \%$ of students from the adjacent courses attended the seminar series of each another motivating it by pure curiosity.

The practical part was structured similarly in all three courses and consists of three stages. At the first stage a handson exercises with Amazon AWS environment were intended to familiarise students key aspects of practical cloud computing. At the second stage a set of course-specific lab assignments emphasised the core practical issues of the particular subject. Finally, at the third stage the knowledge and skills from the previous two phases were applied to execute a corresponding part of the common to the three courses project. All practical stages were carefully synchronised across the three courses so that student groups would avoid unnecessary delays due to dependencies on the results from other student groups.

In order to orchestrate and pace collaboration and the joint progress two concertation meetings for students from all three courses were planed: a.) For agreeing on the common API

\footnotetext{
${ }^{4}$ Adobe Conect. [Online] Available: http://www.adobe.com/products/ adobeconnect.html

${ }^{5}$ Fronter LMS. [Online] Available: http://com.fronter.info/
}

between the subsystems and b.) For integrating the developed parts into a holistic IoT system. In practice students from different courses clustered in groups, which met together outside the scheduled meeting hours in order to synchronously develop the final demonstrator.

Finally, the culmination of the triple-run experiment was a general assembly where all students were gathered in a large auditorium for demonstration and presentation their solutions. We organized this gathering as poster-session where student pitched they solutions to other participants. This event was made open to a wider public both for publicity reasons as well as to give students a feeling of a technology fair.

\section{TECHNOLOGY USED IN TRIPLE-RUN COURSES}

In this section two technology blocks laying the ground for the triple-run experiment are described. In the sensor network course a pedagogy-oriented simulation environment named Symphony [12] was used to give students skills of developing a real sensor network software while reducing the frustration of debugging the code on real hardware.

The practical tasks in all three courses were conducted inside the Amazon Web Services IaaS environment. While students in the D7015E course used Amazon AWS only as a virtual computer to run the Symphony simulator, the students of other two courses experimented with more or less the entire spectrum of the AWS functionality. For the triple-run experiment we received an educational grant from Amazon covering all needs in computing infrastructure for all students in the three courses. In the next section we report the cost details of our approach.

\section{A. Symphony - a Pedagogy Oriented WSN Simulation Frame- work}

Simulation framework Symphony [12] is rooted in the authors' own experience while teaching the D7015E course 
as well as when developing and testing a real-life mediumscale distributed WSN application in the domain of intelligent transportation systems. On the teaching front we were confronted with a dual challenge. On the one hand students really appreciated to work with real WSN software and hardware. On the other hand, however, we observed that students were literally suffering from painful debugging of their (rather simple) distributed network functionality and got frustrated from time consuming reprogramming of devices. Even though at the end most of the students get used to the development environment, we the course instructors understood that this in many cases is done by the cost of devoting less time to conceptual understanding of the problems related to the design, analysis and deployment of resource constrained wireless sensor networks.

An architecture of Symphony is illustrated in Figure 3. It consists of three operating and programming scopes: an operating system (OS) scope, a hardware (HW) scope, and an orchestration and communication scope. The OS scope provides necessary tools and a set of rules for building existing operating systems for sensor devices (e.g. Contiki, TinyOS, FreeRTOS) to a virtual image. To the best of our knowledge Symphony is the only environment where students may seamlessly work with different operating systems in a single experiment avoiding a hustle of installing them on the devices. The HW scope of Symphony contains a set of models accurately emulating time behaviour of hardware components. From the teaching perspective this scope gives a possibility to demonstrate the effect of resource constraint hardware elements on the performance of higher layers' communication protocols, which otherwise is at least challenging if not impossible to demonstrate on real devices. Network simulator $n s-3^{6}$ offers the orchestration and communication scope of Symphony. The choice of a popular network simulator as a provider of communication models allows considering non-trivial network topologies and communication scenarios. Moreover $n s-3$ provides a possibility to run simulations in real-time and establish network connection with any computer connected to the Internet. We utilised this capability of Symphony extensively by letting the students to direct the simulated sensory traffic to the back-end system developed by students from the D7001D class.

Finally, since the framework is executed on a PC a favourite integrated development environment supporting main stream programming languages could be used. This makes experimenting with WSN functionality in Symphony more methodological and less time consuming. Although Symphony could be installed on any physical computer, during the course of the triple-run experiment we ran Symphony in the cloud. The rationale behind executing the simulator in the Amazon AWS is twofold. Firstly, we gave students from the D7015E course a taste of working in the IaaS cloud environment, which was appreciated. Secondly, this choice simplified our assistance to possible technical problems since we as the instructors had full access to the virtual machines of the students. In order to shorten the starting up time we prepared a Virtual Machine Image with all necessary software and development environment pre-installed.

\footnotetext{
${ }^{6}$ Ns-3 simulator, [Online] Available: http://www.nsnam.org/.
}

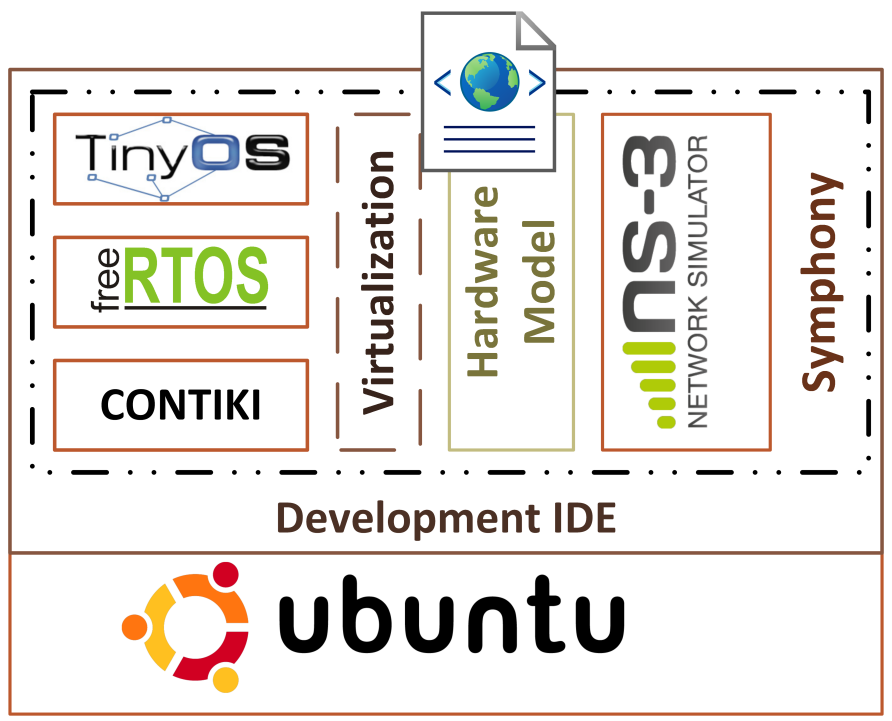

Fig. 3. Symphony framework set up.

\section{B. Amazon AWS as the base computing infrastructure in the triple-run experiment}

The choice of the cloud infrastructure in general and Amazon AWS in particular is rather straightforward. Prior to all we intended to give students skills of working with the cuttingedge platform for production of commercial ICT solutions. Secondly, the flexibility, the diversity and the availability of the Amazon AWS infrastructure go far beyond similar parameters of the university's own. Thirdly, as the courses in question assume programming of rather low level network functionality an IaaS cloud modality, where one gets an access to raw computing resources is virtually the only choice.

While teaching network programming related courses using an IaaS cloud infrastructure infrastructure provides many methodological benefits a substantial amount of time were spent on making the cloud environment ready for education purposes. Amazon AWS being a tool for professional developers needed to be adapted for the triple-run experiments in the following ways. Firstly, we introduced naming conventions for tagging different functional elements, such as authorisation keys, EC2 instances and others. In order to keep the resource usage under control we developed a "cloudcrawler" script, which cleaned up the unused and orphaned resources at scheduled time periods. Although we did not place any restrictions on the usage of a specific operating system we prepared an Ubuntu-based Virtual Machine Image with all necessary network configurations and pre-configured an integrated development environment. The image was available to students before the course began.

\section{REFLECTIONS, LESSONS LEARNEd AND FutURE DEVELOPMENTS}

"The concept with combining three courses is a great one!", "I loved an idea of working on the same project between three course", "To work with real tools and systems, which are currently used in the industry was great!". "It was the first time I've got an impression of working in a company 
with real project, interesting topics, and nice atmosphere in the class ${ }^{7}$. ." These are examples of the overall impression about the triple-run courses, which we got as the result of courses' evaluations by students. Our general impression from the triple-run experiment is overly positive and we definitely will work further towards improving and polishing the concept. In this section we present selected observations we made during the course of the experiment.

The main critique from many students was about their feeling of the work load being un-proportional to the course credits $^{8}$. We analyzed the usage pattern of virtual machines (EC2 instances) available from the Amazon management console as a reference of the actual time an average student spent on programming. The de-facto maximum load in the practical part is approximately 100 hours per student. This number also met our expectations before the course start. We advocate that this feeling comes mainly because of the diversity of techniques the students were offered to use and the nature of open end problems in the practical part. This observation, however, does not increase the student satisfaction index by itself. Our on-going work on the next edition of the triple-run is directed towards improving this situation.

\section{A. Enabling innovative thinking in CS students}

Innovation, as the catalyst to economical growth, is enabled through combining existing products, processes, services and technologies into a unique (novel) constellation, which is more effective for solving a particular problem. Our credo for enabling the innovative thinking in students includes exposing them to technologies outside the boundaries of the particular subject and giving them free hands to solve open end problems.

In particular, for the D7015E sensor networks course we built a line of reasoning for counter-weighing the processing of real data in resource constraint sensor devices (in-network processing) to processing of real-time data in the high-end back-end systems.

The implementation of our "free-hands-on-open-endproblem" concept is best visible in Figure 4 showing the usage pattern of virtual machine resources (EC-2 instances) of different types. At the course start the main concepts were explained using the least powerful Micro instance shown by the green solid line in the chart. Closer to the courses' midterm the students could try the entire palette of cloud functional elements (the dotted red line). Naturally, closer to the end of the course the students converged to an optimal configuration (the dashed blue line), which suits just their needs for implementing their particular design.

\section{B. Issues connected to using Amazon AWS in programming courses}

Although cloud computing is a mature technology, using it for education purposes in programming-related courses is not trivial. The biggest challenge we encountered is unavailability of an easy to use student and resource management facility.

\footnotetext{
${ }^{7}$ An interview with one of the triple-run student, [Online]. Available: http://www.ltu.se/ltu/media/news/Utbildningsnyheter/ Unikt-projekt-lar-studenter-jobba-i-molnet-1.99264?1=en

${ }^{8}$ According to regulations of Swedish Ministry of Higher Education a course worth 7.5 ECTS credits should generate work load amounting to 200 hours.
}

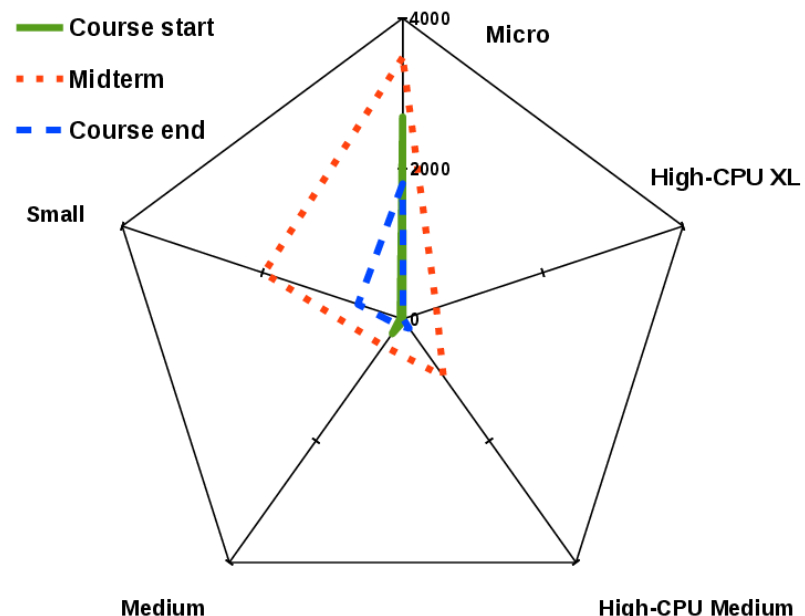

Fig. 4. The de facto work load distribution in terms of hours of usage and types of used EC2 instances.

As a matter of fact the web-based management console of Amazon AWS does not meet the demands of a large group of students with diverse programming skills. For example, when starting an instance of a virtual machine manually, one needs to select an machine image, a security group, and a key pair used for login. With more than 60 students creating own instances under the same AWS account the size of drop-down menus offering functional element quickly became too large making even simple manipulations with the environment long and sometimes frustrating. Although as the course progressed the students started using scripts to manage their resources and the above mentioned issue became less critical, we conjecture that education oriented management tools are a desirable feature in cloud infrastructures.

\section{Economy of the triple-run experiment}

The resulting accounting showed a cost of $\$ 200$ per student for the duration of the trial. In fact this is a first occasion when we can see the real cost of giving a computer science course per student. This information is normally hidden when using University infrastructure. The question whether this cost is appropriate should be considered while weighting the flexibility and possibilities, which the cloud-based infrastructure provides. Figure 5 shows a distribution of costs per different functional elements of Amazon AWS. The resource allocation amongst different Amazon AWS elements was unequally distributed as depicted in the figure. Most monetary resources were consumed by students using the DynoDB data storage component. In fact this element was not critical for the triple-run practical part and was optional to use. It, however, contributed to almost $70 \%$ of all costs. This is due to a very unclear charging model making it difficult to calculate in-front costs when using this resource. Without this component the cost per student would reduce to a much more reasonable $\$ 60$.

\section{CONCLUSIONS}

We presented a teaching experiment named "triple-run". The content and the time line of three courses covering the 


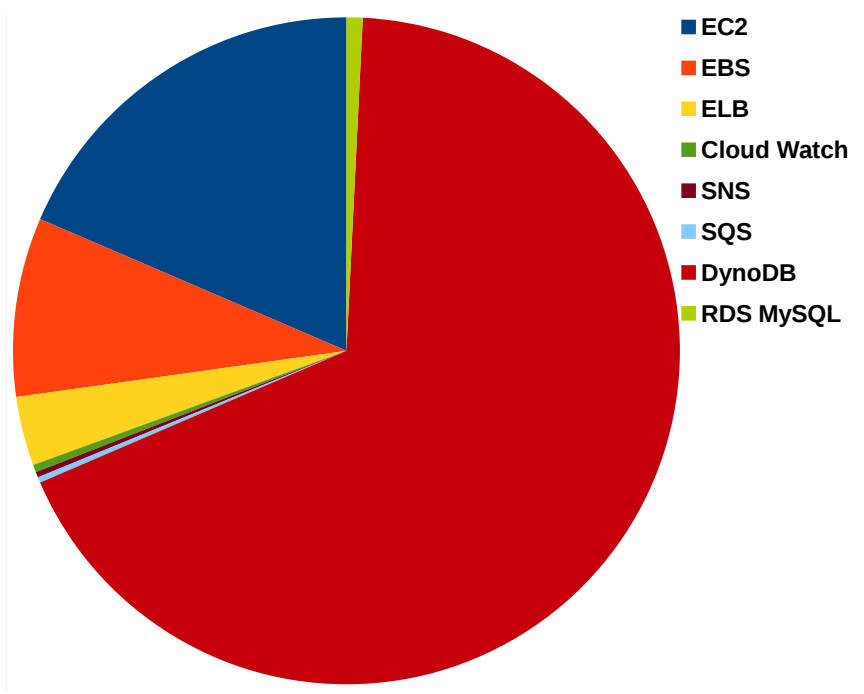

Fig. 5. Distribution of consumed resources per different functional elements in terms of cost.

entire technology chain of Internet of Things were aligned to present a holistic picture to students and enable innovative thinking. The first experiences are definitely positive and we intend to develop and improve the triple-run philosophy further. Main challenges, which remain to address are connected to the logistics of using cloud infrastructure for education purposes.

\section{ACKNOWLEDGEMENT}

We would like to thank all students participating in our experimental courses for their patience, understanding and valuable feedback. Also Amazon AWS for providing educational grant used for these courses.

\section{REFERENCES}

[1] K. Reid and D. Ferguson, "Work in progress: Enhancing the entrepreneurial mindset of freshman engineers," in Frontiers in Education Conference (FIE), 2011, oct. 2011, pp. F2D-1-F2D-3.

[2] H. Berglund and K. Wennberg, "Creativity Among Entrepreneurship Students: Comparing Engineering and Business Education," International Journal of Continuing Engineering Education and Lifelong Learning. (Special Issue on Enterprise), 2006.

[3] M. J. Prince and R. M. Felder, "Inductive teaching and learning methods: Definitions, comparisons, and research bases," Journal of Engineering Education, vol. 95, pp. 123-138, 2006.

[4] D. W. Johnson, R. T. Johnson, and K. A. Smith, "Cooperative Learning Returns To College What Evidence Is There That It Works?" Change: The Magazine of Higher Learning, vol. 30, pp. 26-35, 1998.

[5] M. Daniels, X. Faulkner, and I. Newman, "Open ended group projects, motivating students and preparing them for the 'real world'," in Software Engineering Education and Training, 2002. (CSEE T 2002). Proceedings. 15th Conference on, feb. 2002, pp. 115-126.

[6] R. E. Sabin and E. P. Sabin, "Collaborative learning in an introductory computer science course," in Proceedings of the twenty-fifth SIGCSE symposium on Computer science education, ser. SIGCSE '94. New York, NY, USA: ACM, 1994, pp. 304-308.

[7] E. Ragan, S. Frezza, and J. Cannell, "Product-based learning in software engineering education," in Frontiers in Education Conference, 2009. FIE '09. 39th IEEE, oct. 2009, pp. 1-6.

[8] J. Biggs and C. Tang, Teaching for Quality Learning at University, ser. Society for Research into Higher Education. Open University Press, 112011.

[9] J. Froyd, "Problem-based learning and adaptive expertise," in Frontiers in Education Conference (FIE), 2011, oct. 2011, pp. S3B-1-S3B-5.

[10] G. Kortuem, A. Bandara, N. Smith, M. Richards, and M. Petre, "Educating the internet-of-things generation," Computer, vol. 46, no. 2, pp. 53-61, 2013.

[11] W. Birk, J. Eliasson, P. Lindgren, E. Osipov, and L. Riliskis, "Road Surface Networks technology enablers for enhanced ITS," in Vehicular Networking Conference (VNC), 2010 IEEE, Dec. 2010, pp. 152-159.

[12] L. Riliskis and E. Osipov, "Symphony: Simulation, emulation, and virtualization framework for accurate wsn experimentation," in Software Engineering for Sensor Network Applications (SESENA), 2013 Fourth International Workshop on, 2013, pp. 22-28. 